\title{
Is the Quest for Signaling Bias Worth the Effort?
}

\author{
Terry Kenakin \\ Department of Pharmacology, University of North Carolina School of Medicine, Chapel Hill, North Carolina
}

Received November 17, 2017; accepted January 12, 2018

\section{ABSTRACT}

The question of whether signaling bias is a viable discovery strategy for drug therapy is discussed as a value proposition. On the positive side, bias is easily identified and quantified in simple in vitro functional assays with little resource expenditure. However, there are valid pharmacological reasons why these in vitro bias numbers may not accurately translate to in vivo therapeutic systems making the expectation of direct correspondence of in vitro bias to in vivo systems a problematic process. Presently, in vitro bias is used simply as a means to identify unique molecules to be advanced to more complex therapeutic assays but from this standpoint alone, the value proposition lies far to the positive. However, pharmacological attention needs to be given to the translational gap to reduce inevitable and costly attrition in biased molecule progression.

\section{Is the Quest for Signaling Bias Worth the Effort?}

The ability of different agonists to stabilize different active receptor states can lead to signaling bias whereby some cytosolic signaling pathways are preferentially activated at the expense of others (Kenakin and Morgan, 1989). This effect can: 1) emphasize beneficial signaling pathways, i.e., parathyroid hormone (PTH)-mediated bone building for osteoporosis (Gesty-Palmer and Luttrell, 2011; Gesty-Palmer et al., 2013); 2) de-emphasize harmful signaling pathways, i.e., respiratory depression for opioid analgesics (Raehal et al., 2005; Kelly, 2013; Koblish et al., 2017); 3) de-emphasize harmful pathways and prevent the natural agonist from activing these pathways, i.e., biased angiotensin blockers for heart failure (Violin et al., 2006, 2010); and 4) allow pursuit of previously forbidden drug targets due to side effects, i.e., $\kappa$-opioid receptor analgesics (White et al., 2014; Brust et al., 2016). The consideration of biased signaling has revitalized seven transmembrane receptors as therapeutic drug targets (Kenakin, 2015b); from this point of view, bias is a strategy to improve drug therapy. However, there are clear challenges to the pursuit of signaling bias elegantly elucidated in the paper by Michel and Charlton, leaving the following question: is bias a practical way forward for drug discovery at this time? It is worth considering biased signaling in terms of a value proposition.

Ideally, enough information about cell signaling should be available to design a target bias profile. The first viable biased ligand, [Sar1, Ile4, Ile8]-AngII (and later the analog D-Alanine,N-methylglycyl-L-arginyl-L-valyl-L-tyrosylL-isoleucyl-L-histidyl-L-prolyl) was designed with a defined

\footnotetext{
https://doi.org/10.1124/mol.117.111187.
}

profile of $\beta$-arrestin activation and absence of $\mathrm{G}_{\mathrm{q}}$ protein activation for congestive heart failure (Wei et al., 2003), and there have been many other similar proposals for other molecules (i.e., opioid analgesics and other agonists). However, as discussed by Michel and Charlton, our knowledge of signaling is still insufficient to adequately predict how the bias observed in signaling assays will translate to in vivo therapy for most receptors, leaving a large translational gap between in vitro definition and in vivo activity. The reasons for this gap relate to the differences between the simple isolated pathway assays used to detect bias and the eminently more complicated systems in vivo in which this bias must make a difference.

Agonist bias is most commonly revealed as differences in agonist relative potency [either potency ratios for full agonists or $\log \left(\tau / K_{\mathrm{A}}\right)$ or $\log \left(\max / \mathrm{EC}_{50}\right)$ values for full and partial agonists] (Kenakin, 2017). In fact, in the 1980s diversity in relative potencies was the first sign that Stephenson's model of a single receptor active state need not be the singular mechanism for agonism; these published reports were harbingers of biased signaling (i.e., see Roth and Chuang, 1987). The simple model of selective stabilization of different receptor active states accommodates the various effects seen in functional in vitro assays. However, differences in potency ratios with cell type (Christmanson et al., 1994), stoichiometry in receptors and G proteins (Watson et al., 2000), and measurement of agonist signals at different points along the stimulus-response cascade (Peters et al., 2007; Peters and Scott, 2009) also indicate that this bias can change with disposition of the receptor stimulus beyond the allosteric vector of agonist/receptor/signaling protein, i.e., functional systems modify bias. The dissociation comes from the fact 
that in vitro bias measured in single functional pathway assays such as second messenger or bioluminescence resonance energy transfer association assays quantifies the differences in allosteric vectors characterizing the ternary complex. These numbers are made up of $\alpha$ and $\beta$ values for probe-dependent allostery (Kenakin, 2015a), and thus adhere to fairly stable molecular rules (with comparison with reference agonists, system and assay bias cease to be an issue). However, once these diverse signals escape the ternary complex and make their way into the cytosol, the cellular milieu can modify them in cell- and system-dependent ways, and thus the stable allosteric-based quantification of vector bias dissociates from cellular signaling (Kenakin and Christopoulos, 2013; Kenakin, 2016). In fact, a shortlist of how system modification of vector bias can be modified includes differences in the following

- Cell-type background;

- Relative stoichiometry of receptors to signaling proteins;

- Cell density of receptors;

- Temporal profiles of different cell signals; and

- Whether agonist potency is affinity or efficacy based.

Therefore, there are good pharmacological reasons why simple in vitro bias will fail to translate accurately to in vivo systems. In view of this potential hazard, how can in vitro bias add value to a drug discovery program?

An answer to this question may lie in the practical way in which bias is used in industrial and academic drug discovery, namely, as a means to identify different molecules. A general theme in discovery and development is that the more complex the assay, the more textured the output. Thus, a series of agonists elevating cytosolic cAMP levels may simply differ in the strength of the signal they produce but otherwise appear to be doing the same thing. In contrast, these same agonists, when put into more complex assays (i.e., in vivo) where many other systems come into play, may diversify; i.e., efficacy can vary in quality as well as quantity. Therefore, identifying fundamentally different agonists (i.e., those that stabilize different receptor active states) in simple in vitro bias assays becomes a cost effective way of choosing the optimal molecules to advance from a screen to a more complex assay. Using this approach the probability of revealing different phenotype responses in complex therapeutic assays will be much higher than if only the most potent hits from a single assay screen are blindly progressed.

It is well established that efficacy is pluridimensional (Galandrin and Bouvier, 2006), i.e., agonists most often have many efficacies in terms of activation of different signaling pathways, and these elements can be identified in bias assays. These combinations of signal pathway activation profiles can be depicted as radar plots, i.e., webs of efficacy (Evans et al., 2010; Zhou et al., 2013), or clustered groups (Huang et al., 2009; Kenakin, 2015b), and when this is done it is seen that every agonist tested has a unique efficacy fingerprint. The elements of these fingerprints are what cells use to produce a mixed phenotypic response, rather like a mixture of primary colors to yield a subtle hue (see Fig. 1). Thus, simple bias numbers may function as a code for complex cellular phenotype responses. Once a particular hue (phenotype cell response) is identified as beneficial then medicinal chemistry can be employed to optimize it. However, such complex outputs may be difficult to systematically modify, raising another possible benefit of in vitro bias profiles. Specifically, if the cellular phenotype could be deconstructed to the mixture of elements (i.e., signaling pathways and the relative activation of these through bias), then these simple systems may be used to more easily manipulate efficacy quality through medicinal chemistry.

In vitro bias can readily be identified and quantified to characterize agonists. The quantification processes differ slightly depending on whether affinity and efficacy are considered in the measurement or whether only efficacy is used (Kenakin et al., 2012; Kenakin and Christopoulos, 2013; Kenakin, 2014; Onaran et al., 2017); however, the differences are usually minor and do not affect identification of exemplar molecules. In light of the other pitfalls in translation of in vitro bias to in vivo systems, the expectation that in vitro bias numbers represent immutable codes becomes relatively unimportant; experience suggests it is probably best to progress biased molecules into the therapeutically relevant systems as soon as possible and not waste time and resources on model systems.

Signaling bias has been verified in many systems and studied by many experimental groups over the years where it has been given a variety of names, i.e., stimulus trafficking (Kenakin, 1995), functional dissociation (Whistler et al., 1999), biased agonism (Jarpe et al., 1998), biased inhibition (Kudlacek et al., 2002), differential engagement (Manning, 2002), discrete activation of transduction (Gurwitz et al., 1994), functional selectivity (Lawler et al., 1999; Kilts et al., 2002; Shapiro et al., 2003), and ligand directed signaling (Michel and Alewijnse, 2007), but everyone basically was and is talking about the same thing. The effect was discovered through the observation that the single active state mechanism for response, which spawned the pharmacological tool of agonist potency ratio, is not the only mechanism available to physiology for production of agonist response. To date, biased agonism has been shown to be a ubiquitous mechanism in pharmacology even used by natural systems to fine tune signaling (Kohout et al., 2004), and at present it is impossible

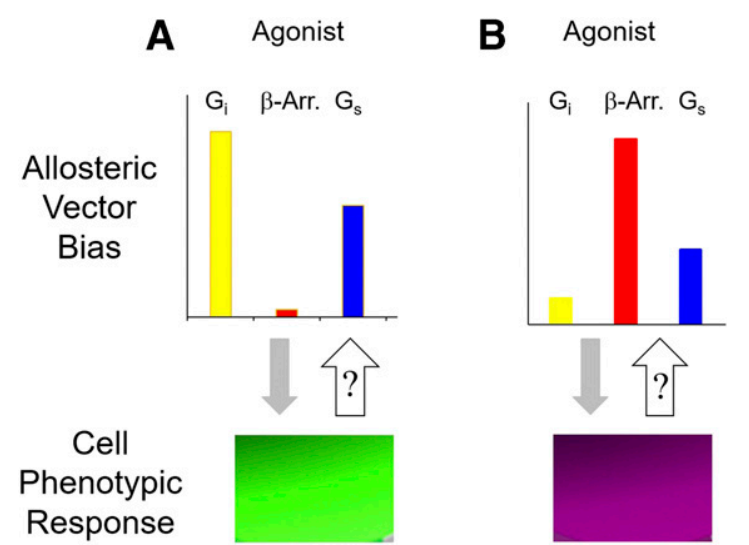

Fig. 1. Cells mix receptor stimuli produced by agonists to yield a complex synoptic response that defines the true therapeutic utility of the agonist. Thus, different biases in terms of elemental signaling pathways can produce different phenotypic cell responses; however, this also allows the cell to hijack various in vitro bias signatures and change them in accordance with the stoichiometry of receptor to signal protein. Once a useful phenotype has been identified, reduction of that phenotype to the in vitro bias signature codes may facilitate medicinal chemical modification of these complex phenotypes. 
to prove that a given receptor will not demonstrate signaling bias. In general, it is a readily discoverable and ubiquitous property of any molecule that could add value in the compound progression process. From this standpoint, the value proposition for determining bias falls heavily toward the positive. However, the problems of translation still remain and predict failures of biased molecules in therapeutic systems. There are certain approaches that can be taken to mitigate the translational hazards and perhaps reduce attrition at this stage.

One factor determining the robustness of a measured bias across different tissue systems is common to all agonist programs, namely, the comparison of the efficacy of the synthetic (biased) agonist to that of the natural endogenous agonist. High potency can be achieved either through high affinity or high efficacy but the ability of agonists to activate a range of tissues with varying sensitivity is dependent on whether efficacy or affinity is the main potency factor. For example, a low affinity/high efficacy agonist such as the $\alpha$-adrenoceptor agonist oxymetazoline is a more potent agonist than norepinephrine in sensitive tissues (it has a positive potency bias) but reverts to being less active in less sensitive tissues (bias reverts to norepinephrine being more sensitive) (Kenakin, 1984); the same effect will be true for biased signaling. Thus, a biased agonist depending on high affinity will essentially "run out of gas" in less sensitive tissues. From this standpoint, it should be noted that bias numbers only describe differences when response is observed but do not predict whether agonism will be observed; this remains in the realm of efficacy (Kenakin, 2015c). Ostensibly, this may suggest that efficacy-based scales of bias are better suited for discovery (Onaran et al., 2017). However, efficacy-based scales fail when full agonism is observed for both pathways since no differentiation between agonists can then be achieved without an independent estimate of agonist affinity, and this is problematic (Kenakin et al., 2012; Kenakin, 2014; Kenakin and Christopoulos, 2013). Once bias has been established, separate experiments should be done to quantify the relative efficacies of the signals. In this regard, the limits of these bias numbers need to be realized. For instance, the lack of observed signaling in a pathway is not indicative of perfect bias but rather simply of insufficient assay sensitivity; methods are available to estimate a minimal estimated bias under these conditions (Stahl et al., 2015; Kenakin, 2015c).

Another fruitful approach to reduce translation attrition is discussed by Michel and Charlton, namely, gaining more detailed knowledge of cell signaling. For example, the effects of biased PTH agonists have been studied for downstream stimulus-response cascade effects. Specifically, the $\beta$-arrestin signaling activity of hPTH(1-34) versus that of the $\beta$-arrestin biased analog [D-Trp $\left.{ }^{12}, \mathrm{Tyr}^{34}\right]-\mathrm{bPTH}(7-34)$ can further be differentiated in terms of transcriptomic signatures in different tissues (the $\beta$-arrestin biased signal differentiates further down the cellular stimulus-response cascade); this type of fine tuning in terms of bias characterization may reduce the failure rate of biased molecules in the translational process (Maudsley et al., 2016). The application of label-free signaling technology (i.e., integrative pharmacology-on-target methods) can further link in vitro bias estimates with in vivo cell-type diversity to further predict in vivo biased effects (Ferrie et al., 2011; Morse et al., 2011; Deng et al., 2013).

The information available to date suggests that there are valid pharmacological reasons for predicted failure in the translation of in vitro to in vivo bias. In addition, the theoretical advantages of biased signaling have yet to be realized therapeutically. In spite of these negatives, the promise far outweighs the cost since the insertion of in vitro screens into the discovery process to identify exemplar molecules is relatively minor and the potential benefits are large. The increasing knowledge of complex signaling networks also augurs that better targeting of biased molecules is yet to come. Thus, the value proposition at this point suggests that a quest for biased signaling is worth the effort but also compels increasing attention to the translation of simple in vitro bias to whole cell and whole body systems.

\section{Authorship Contributions}

Wrote or contributed to the writing of the manuscript: Kenakin.

\section{References}

Brust TF, Morgenweck J, Kim SA, Rose JH, Locke JL, Schmid CL, Zhou L, Stahl EL, Cameron MD, Scarry SM, et al. (2016) Biased agonists of the kappa opioid receptor suppress pain and itch without causing sedation or dysphoria. Sci Signal 9:ra117. Christmanson L, Westermark P, and Betsholtz C (1994) Islet amyloid polypeptide stimulates cyclic AMP accumulation via the porcine calcitonin receptor. Biochem Biophys Res Commun 205:1226-1235.

Deng H, Sun H, and Fang Y (2013) Label-free cell phenotypic assessment of the biased agonism and efficacy of agonists at the endogenous muscarinic M3 receptors. J Pharmacol Toxicol Methods 68:323-333.

Evans BA, Sato M, Sarwar M, Hutchinson DS, and Summers RJ (2010) Liganddirected signalling at $\beta$-adrenoceptors. Br J Pharmacol 159:1022-1038.

Ferrie AM, Sun H, and Fang Y (2011) Label-free integrative pharmacology on-target of drugs at the $\beta_{2}$-adrenergic receptor. Sci Rep 1:33.

Galandrin S and Bouvier M (2006) Distinct signaling profiles of $\beta_{1}$ and $\beta_{2}$ adrenergic receptor ligands toward adenylyl cyclase and mitogen-activated protein kinase reveals the pluridimensionality of efficacy. Mol Pharmacol 70:1575-1584.

Gesty-Palmer D and Luttrell LM (2011) 'Biasing' the parathyroid hormone receptor: a novel anabolic approach to increasing bone mass? Br J Pharmacol 164:59-67.

Gesty-Palmer D, Yuan L, Martin B, Wood WH, III, Lee MH, Janech MG, Tsoi LC, Zheng WJ, Luttrell LM, and Maudsley S (2013) $\beta$-Arrestin-selective G proteincoupled receptor agonists engender unique biological efficacy in vivo. Mol Endocrinol 27:296-314.

Gurwitz D, Haring R, Heldman E, Fraser CM, Manor D, and Fisher A (1994) Discrete activation of transduction pathways associated with acetylcholine $\mathrm{m} 1$ receptor by several muscarinic ligands. Eur J Pharmacol 267:21-31.

Huang XP, Setola V, Yadav PN, Allen JA, Rogan SC, Hanson BJ, Revankar C, Robers M, Doucette C, and Roth BL (2009) Parallel functional activity profiling reveals valvulopathogens are potent 5-hydroxytryptamine ${ }_{2 \mathrm{~B}}$ receptor agonists: implications for drug safety assessment. Mol Pharmacol 76:710-722.

Jarpe MB, Knall C, Mitchell FM, Buhl AM, Duzic E, and Johnson GL (1998) [D-Arg ${ }^{1}$, D-Phe ${ }^{5}$, D-Trp ${ }^{7,9}$, Leu $^{11}$ ]Substance P acts as a biased agonist toward neuropeptide and chemokine receptors. $J$ Biol Chem 273:3097-3104.

Kelly E (2013) Efficacy and ligand bias at the $\mu$-opioid receptor. Br J Pharmacol 169: 1430-1446.

Kenakin T (1995) Agonist-receptor efficacy. II. Agonist trafficking of receptor signals. Trends Pharmacol Sci 16:232-238.

Kenakin T (2014) What is pharmacological 'affinity'? Relevance to biased agonism and antagonism. Trends Pharmacol Sci 35:434-441.

Kenakin T (2015a) Gaddum Memorial Lecture 2014: receptors as an evolving concept: from switches to biased microprocessors. Br J Pharmacol 172:4238-4253.

Kenakin T (2015b). New lives for seven transmembrane receptors as drug targets. Trends Pharmacoll Sci 36:705-706.

Kenakin T (2015c) The effective application of biased signaling to new drug discovery. Mol Pharmacol 88:1055-1061.

Kenakin T (2017) A scale of agonism and allosteric modulation for assessment of selectivity, bias, and receptor mutation. Mol Pharmacol 92:414-424.

Kenakin T and Christopoulos A (2013) Signalling bias in new drug discovery: detection, quantification and therapeutic impact. Nat Rev Drug Discov 12:205-216.

Kenakin T, Watson C, Muniz-Medina V, Christopoulos A, and Novick S (2012) A simple method for quantifying functional selectivity and agonist bias. ACS Chem Neurosci 3:193-203.

Kenakin TP (1984) The relative contribution of affinity and efficacy to agonist activity: organ selectivity of noradrenaline and oxymetazoline with reference to the classification of drug receptors. Br J Pharmacol 81:131-141.

Kenakin TP (2016) Synoptic pharmacology: detecting and assessing the pharmacological significance of ligands for orphan receptors. Pharmacol Res 114:284-290.

Kenakin TP and Morgan PH (1989) Theoretical effects of single and multiple transducer receptor coupling proteins on estimates of the relative potency of agonists. Mol Pharmacol 35:214-222.

Kilts JD, Connery HS, Arrington EG, Lewis MM, Lawler CP, Oxford GS, O'Malley KL, Todd RD, Blake BL, Nichols DE, et al. (2002) Functional selectivity of dopamine receptor agonists. II. Actions of dihydrexidine in $\mathrm{D}_{2 \mathrm{~L}}$ receptor-transfected MN9D cells and pituitary lactotrophs. J Pharmacol Exp Ther 301:1179-1189.

Koblish M, Carr R, III, Siuda ER, Rominger DH, Gowen-MacDonald W, Cowan CL, Crombie AL, Violin JD, and Lark MW (2017) TRV0109101, a G protein-biased 
agonist of the $\mu$-opioid receptor, does not promote opioid-induced mechanical allodynia following chronic administration. J Pharmacol Exp Ther 362:254-262.

Kohout TA, Nicholas SL, Perry SJ, Reinhart G, Junger S, and Struthers RS (2004) Differential desensitization, receptor phosphorylation, beta-arrestin recruitment, and ERK1/2 activation by the two endogenous ligands for the CC chemokine receptor 7. J Biol Chem 279:23214-23222.

Kudlacek O, Waldhoer M, Kassack MU, Nickel P, Salmi JI, Freissmuth M, and Nanoff $\mathrm{C}$ (2002) Biased inhibition by a suramin analogue of $\mathrm{A}_{1}$-adenosine receptor/G protein coupling in fused receptor/G protein tandems: the $\mathrm{A}_{1}$-adenosine receptor is predominantly coupled to $\mathrm{Go}_{\alpha}$ in human brain. Naunyn Schmiedebergs Arch Pharmacol 365:8-16.

Lawler CP, Prioleau C, Lewis MM, Mak C, Jiang D, Schetz JA, Gonzalez AM, Sibley DR, and Mailman RB (1999) Interactions of the novel antipsychotic aripiprazole (OPC-14597) with dopamine and serotonin receptor subtypes. Neuropsychopharmacology 20:612-627.

Manning DR (2002) Measures of efficacy using G proteins as endpoints: differential engagement of G proteins through single receptors. Mol Pharmacol 62:451-452.

Maudsley S, Martin B, Janssens J, Etienne H, Jushaj A, van Gastel J, Willemsen A, Chen H, Gesty-Palmer D, and Luttrell LM (2016) Informatic deconvolution of biased GPCR signaling mechanisms from in vivo pharmacological experimentation. Methods 92:51-63.

Michel MC and Alewijnse AE (2007) Ligand-directed signaling: 50 ways to find a lover. Mol Pharmacol 72:1097-1099.

Michel MC and Charlton SJ (2018) Biased agonism in drug discovery - is it too soon to choose a path? Mol Pharmacol 117:259-265.

Morse M, Tran E, Sun H, Levenson R, and Fang Y (2011) Ligand-directed functional selectivity at the mu opioid receptor revealed by label-free integrative pharmacology on-target. PLoS One 6:e25643.

Onaran HO, Ambrosio C, Uğur Ö, Madaras Koncz E, Grò MC, Vezzi V, Rajagopal S, and Costa T (2017) Systematic errors in detecting biased agonism: analysis of current methods and development of a new model-free approach. Sci Rep 7:44247.

Peters MF, Knappenberger KS, Wilkins D, Sygowski LA, Lazor LA, Liu J, and Scott CW (2007) Evaluation of cellular dielectric spectroscopy, a whole-cell, label-free technology for drug discovery on $\mathrm{G}_{\mathrm{i}}$-coupled GPCRs. J Biomol Screen 12:312-319.

Peters MF and Scott CW (2009) Evaluating cellular impedance assays for detection of GPCR pleiotropic signaling and functional selectivity. J Biomol Screen 14:246-255.

Raehal KM, Walker JK, and Bohn LM (2005) Morphine side effects in $\beta$-arrestin

2 knockout mice. J Pharmacol Exp Ther 314:1195-1201.
Roth BL and Chuang DM (1987) Multiple mechanisms of serotonergic signal transduction. Life Sci 41:1051-1064.

Shapiro DA, Renock S, Arrington E, Chiodo LA, Liu LX, Sibley DR, Roth BL and Mailman R (2003) Aripiprazole, a novel atypical antipsychotic drug with a unique and robust pharmacology. Neuropsychopharmacology 28:1400-1411.

Stahl EL, Zhou L, Ehlert FJ, and Bohn LM (2015) A novel method for analyzing extremely biased agonism at $\mathrm{G}$ protein-coupled receptors. Mol Pharmacol 87:866-877.

Violin JD, Dewire SM, Barnes WG, and Lefkowitz RJ (2006) G protein-coupled receptor kinase and $\beta$-arrestin-mediated desensitization of the angiotensin II type $1_{\mathrm{A}}$ receptor elucidated by diacylglycerol dynamics. J Biol Chem 281:36411-36419.

Violin JD, DeWire SM, Yamashita D, Rominger DH, Nguyen L, Schiller K, Whalen EJ, Gowen M, and Lark MW (2010) Selectively engaging $\beta$-arrestins at the angiotensin II type 1 receptor reduces blood pressure and increases cardiac performance. J Pharmacol Exp Ther 335:572-579.

Watson C, Chen G, Irving P, Way J, Chen WJ, and Kenakin T (2000) The use of stimulusbiased assay systems to detect agonist-specific receptor active states: implications for the trafficking of receptor stimulus by agonists. Mol Pharmacol 58:1230-1238.

Wei H, Ahn S, Shenoy SK, Karnik SS, Hunyady L, Luttrell LM, and Lefkowitz RJ (2003) Independent $\beta$-arrestin 2 and G protein-mediated pathways for angiotensin II activation of extracellular signal-regulated kinases 1 and 2. Proc Natl Acad Sci USA 100:10782-10787.

Whistler JL, Chuang HH, Chu P, Jan LY, and von Zastrow M (1999) Functional dissociation of mu opioid receptor signaling and endocytosis: implications for the biology of opiate tolerance and addiction. Neuron 23:737-746.

White KL, Scopton AP, Rives ML, Bikbulatov RV, Polepally PR, Brown PJ, Kenakin T, Javitch JA, Zjawiony JK, and Roth BL (2014) Identification of novel functionally selective $\kappa$-opioid receptor scaffolds. Mol Pharmacol 85:83-90.

Zhou L, Lovell KM, Frankowski KJ, Slauson SR, Phillips AM, Streicher JM, Stahl E, Schmid CL, Hodder P, Madoux F, et al. (2013) Development of functionally selective, small molecule agonists at kappa opioid receptors. J Biol Chem 288: 36703-36716.

Address correspondence to: Dr. Terry Kenakin, Department of Pharmacology, University of North Carolina School of Medicine, 120 Mason Farm Road, Room 4042, Genetic Medicine Building, CB\# 7365, Chapel Hill, NC 27599-7365. E-mail: kenakin@email.unc.edu 